\title{
Arterial oxygenation during sleep in patients with right-to-left cardiac or intrapulmonary shunts
}

\author{
JR CATTERALL, NJ DOUGLAS, PMA CALVERLEY, CM SHAPIRO, DC FLENLEY \\ From the Departments of Respiratory Medicine and Medicine, University of Edinburgh
}

ABSTRACT We have studied arterial oxygen saturation $\left(\mathrm{SaO}_{2}\right)$, breathing patterns, and electroencephalographic (EEG) sleep stage during nocturnal sleep in six patients with right-to-left cardiac or intrapulmonary shunts and six patients with chronic bronchitis and emphysema, chosen because they were equally hypoxaemic when awake $\left(\mathrm{SaO}_{2}\right.$ during wakefulness: bronchitis 74 $90 \%$, mean $83 \%$; shunt $77-89 \%$, mean $83 \%$ ). The patients with bronchitis had far greater falls in $\mathrm{SaO}_{2}$ when asleep than those with shunts (maximum fall in $\mathrm{SaO}_{2}$ during sleep: bronchitis $14-47 \%$, mean $29 \%$; shunt $5-10 \%$, mean $8 \%$; $<<0.01$ ). Significant episodes of hypoxaemia (defined as $\mathrm{SaO}_{2}$ falls $>10 \%$ ) occurred in all six bronchitic patients, from once to seven times per night, but in none of the patients with shunts $(p<0.05)$. Twenty-four of the 27 episodes of hypoxaemia occurred in rapid-eye-movement (REM) sleep and 24 were associated with hypopnoea. The two groups of patients had similar EEG sleep patterns and the same amount of hypopnoea during sleep. Thus the level of arterial oxygenation when the patient is awake is not the sole determinant of the degree of nocturnal hypoxaemia; the pathological process is also important.

Transient hypoxaemia occurs during sleep in patients with a variety of respiratory diseases, including chronic bronchitis and emphysema, ${ }^{1-5}$ asthma, ${ }^{6-7}$ and cystic fibrosis. ${ }^{89}$ Furthermore, at high altitude even healthy people have considerable falls in arterial oxygen saturation $\left(\mathrm{SaO}_{2}\right)$ during sleep. ${ }^{1011}$ If severe, such nocturnal hypoxaemia may be important in the development of secondary polycythaemia $^{12}$ and pulmonary hypertension. ${ }^{12}{ }^{13}$ Most of these hypoxaemic episodes result from hypoventilation rather than sleep apnoea, and we have recently shown that the degree of arterial oxygen desaturation in sleep is largely determined by the level of arterial oxygenation when the patient is awake, ${ }^{414}$ as those who are most hypoxaemic when awake start the night on the steep part of the oxyhaemoglobin dissociation curve.

We have now sought to explore this relationship between daytime and nocturnal hypoxaemia in patients whose daytime hypoxaemia arises from right-to-left pulmonary or intracardiac shunts and not primary disease of pulmonary airways.

Address for reprint requests: JR Catterall, Department of Respiratory Medicine, City Hospital, Edinburgh EH10 5SB.

Accepted 10 January 1983

\section{Methods}

We have studied six patients with right-to-left shunts (one man and five women) and six patients with chronic bronchitis and emphysema (two men and four women). The bronchitic patients-mean age 56 years, range $47-62-$ were older than the patients with shunts-mean age 43 years, range $30-57(\mathrm{p}<0.05)$; but the resting $\mathrm{SaO}_{2}$ during wakefulness (measured for 15 minutes with the subject sitting in bed immediately before each study) was similar in the two groups, ranging from $74 \%$ to $90 \%$ (mean $83 \%$ ) in the patients with shunts and from $77 \%$ to $89 \%$ (mean $84 \%$ ) in the bronchitic patients. They all had secondary polycythaemia, the packed cell volume ranging from 0.51 to 0.60 (mean 0.55 ) in the patients with shunts and from 0.44 to 0.61 (mean 0.52 ) in the patients with bronchitis. One of the patients with shunts had pulmonary arteriovenous fistulas in association with hereditary haemorrhagic telangiectasia and the other five had congenital abnormalities of the heart or great vessels (table 1). All the bronchitic patients had severe irreversible airways obstruction with a forced expiratory volume in one second $\left(\mathrm{FEV}_{1}\right)$ of less than 1.01 and they had the "blue and bloated" (type B) pattern of the disease, ${ }^{15}$ being hypoxic, with an arter- 
Table 2 Electroencephalographic sleep stages, irregular breathing, and oxygen desaturation during sleep in six patients with right-to-left cardiac or intrapulmonary shunts and six patients with chronic bronchitis and emphysema

\begin{tabular}{|c|c|c|c|c|c|c|}
\hline \multirow[b]{2}{*}{ Patient No } & \multicolumn{2}{|c|}{ Sleep time $(\min )^{*}$} & \multirow[b]{2}{*}{$\begin{array}{l}\text { No of apnoeic } \\
\text { episodes per } \\
\text { night }\end{array}$} & \multirow[b]{2}{*}{$\begin{array}{l}\text { Total irregular } \\
\text { breathing (min) }\end{array}$} & \multirow[b]{2}{*}{$\begin{array}{l}\text { Maximum fall in } \mathrm{SaO}_{2} \\
\text { from "awake" level } \\
\text { (\%) }\end{array}$} & \multirow[b]{2}{*}{$\begin{array}{l}\text { No of hypoxaemic } \\
\text { episodes } \dagger \\
\text { per night }\end{array}$} \\
\hline & $\overline{\text { Total }}$ & Non-REM REM & & & & \\
\hline
\end{tabular}

Right-to-left shunt

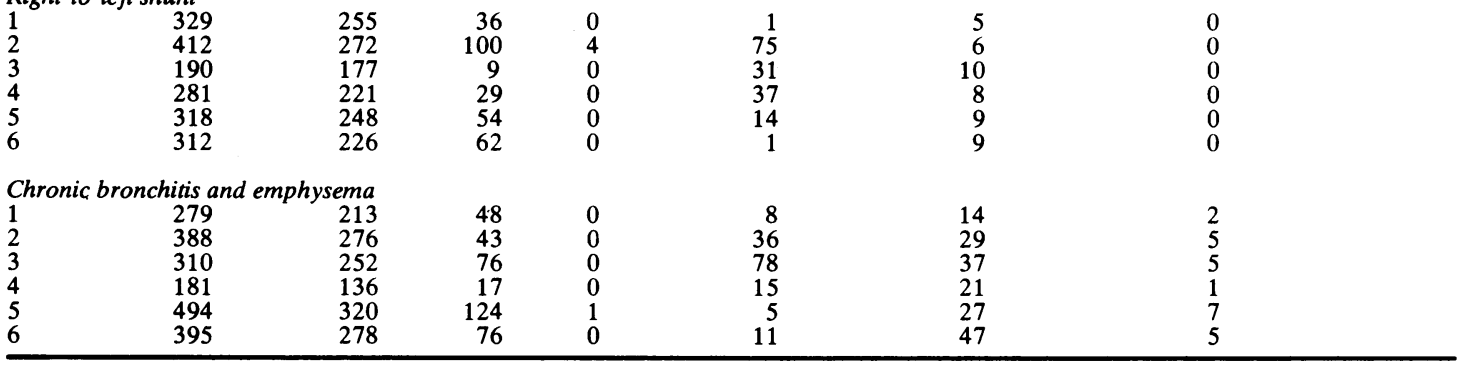

*Total sleep time: total time spent in EEG sleep 1,2,3, and 4; non-rapid eye-movement (non-REM) sleep: EEG sleep stages 2,3 ,and 4. †Fall in $\mathrm{SaO}_{2} 10 \%$ from immediately preceding stable baseline $\mathrm{SaO}_{2}$ during sleep.

apnoeic episodes. Hypopnoea occurred much more frequently than apnoea, and accounted for over $98 \%$ of the total number of episodes of irregular breathing in each patient. Only five apnoeic episodes were recorded in the whole study, and these were all of central type.

In the 12 patients the $\mathrm{SaO}_{2}$ averaged $83 \%$ when they were awake and was not significantly different in the two groups. Hypoxaemia occurred much less often when they were asleep and was much less severe in the patients with shunts. We have defined a significant hypoxaemic episode as a fall in $\mathrm{SaO}_{2}$ greater than $10 \%$ from the immediately preceding stable baseline $\mathrm{SaO}_{2}$ during sleep. ${ }^{2}$ No such episodes were seen in the patients with shunts, whereas hypoxaemic episodes occurred in all six bronchitic patients, from once to seven times a night $(p<0.05$; fig 1). The lowest $\mathrm{SaO}_{2}$ during sleep was $85-65 \%$ (mean $76 \%$ ) in the patients with shunts, compared with $75-30 \%$ (mean 53\%) in the bronchitic patients
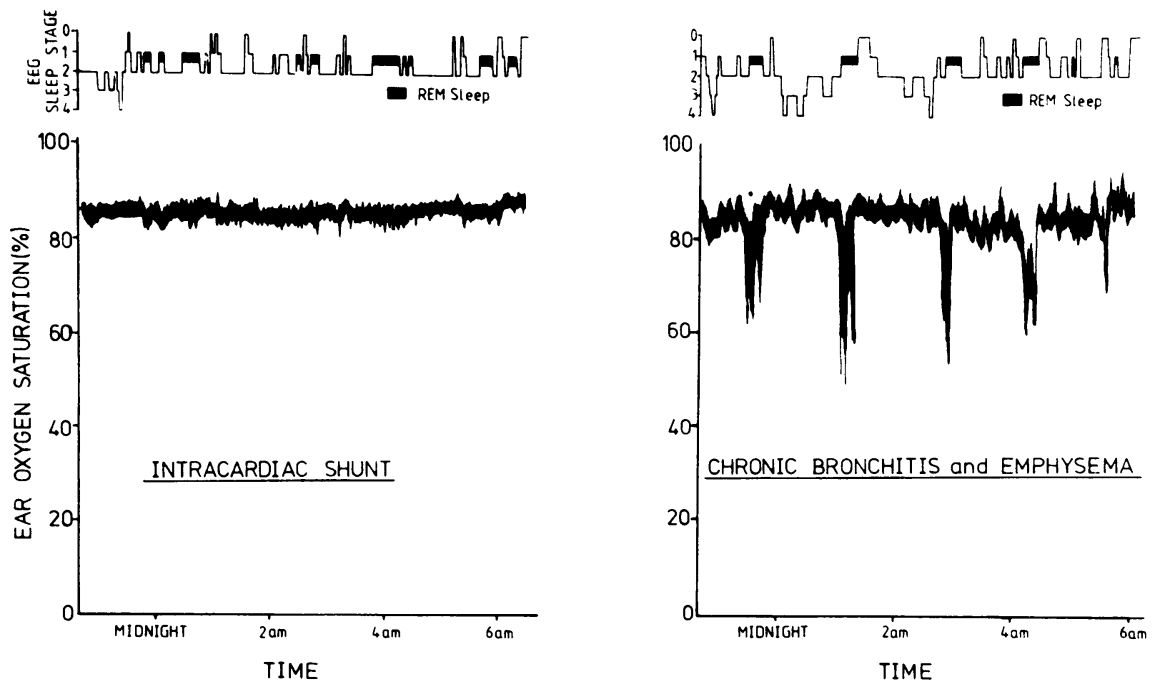

Fig 1 Oxygen saturation ( $\mathrm{SaO}_{2}$; earoximeter) and EEG sleep stage throughout the night in a 52-year-old man with chronic bronchitis and emphysema (right) whose SaO when awake was $85 \%$ and in a 50-year-old man with right-to-left cardiac shunt (left) whose $\mathrm{SaO}_{2}$ when awake was $87 \%$. 


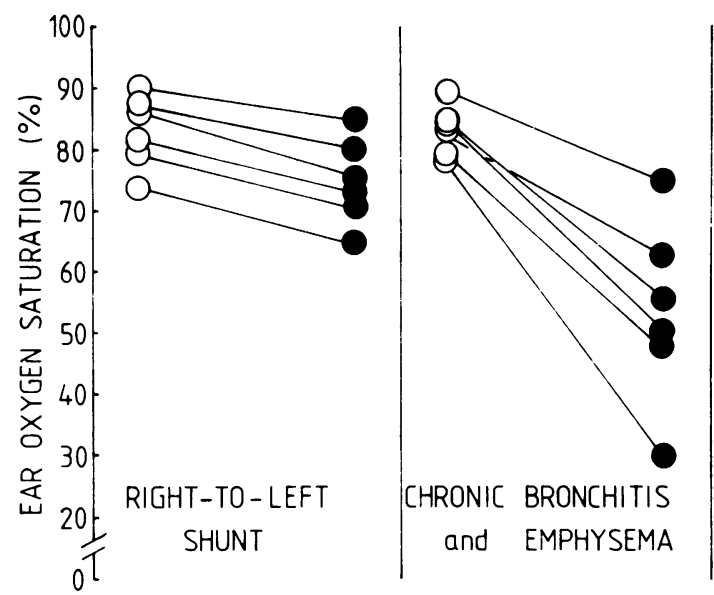

Fig 2 Oxygen saturation (ear oximeter) before sleep (O) and lowest during sleep (O) in six patients with chronic bronchitis and emphysema and six patients with right-to-left shunts.

$(\mathrm{p}<0.02)$. In the former the mean fall in $\mathrm{SaO}_{2}$ from the "awake" level to the lowest level during sleep was $8 \%(5-10 \%)$, much less than the mean fall of $29 \%(14-47 \%)$ in the bronchitic patients $(p<0.01$, fig 2).

Of the 27 hypoxaemic episodes in the bronchitic patients, 24 occurred in REM sleep and three during EEG sleep stage 2 . Chest wall movement was reduced in all 27 episodes, and hypopnoea (as defined above) occurred in 24 of these 27 hypoxaemic episodes.

\section{Discussion}

We have found that patients with daytime hypoxaemia due to right-to-left cardiovascular shunts maintain a higher level of arterial oxygenation during sleep than do patients with chronic bronchitis and emphysema, despite similar degrees of daytime hypoxaemia. Thus the arterial oxygen tension during wakefulness is not the only factor which determines the severity of any nocturnal hypoxaemia. ${ }^{414}$

None of the patients had a sleep apnoea syndrome as defined by Guilleminault. ${ }^{19}$ Hypoxaemia may occur during sleep in patients who do not have sleep apnoea, and although the exact mechanism is still debated hypoventilation seems to be the major factor. ${ }^{14}$ Such hypoventilation usually occurs repeatedly during REM sleep and is also seen in healthy people. ${ }^{142021}$ In $24(89 \%)$ of the 27 hypoxaemic episodes in the bronchitic patients the breathing pattern met our strict criteria for hypopnoea. The patients with shunts, although younger than the bronchitics, ${ }^{21}$ showed hypopnoea of similar duration and severity. The breathing patterns in the two groups were indistinguishable, but the effect on alveolar ventilation could be quantitatively different in the two groups because of their different ventilatory mechanics; and indeed the patients with shunts showed little fall in oxygen saturation during the periods of hypopnoea. This probably arose because only part of the right ventricular output in patients with right-to-left shunts is exposed to alveolar gas, and any change in alveolar oxygen tension (which would fall in hypoventilation) affects only that blood which passes through the pulmonary capillaries Furthermore, the blood which does leave the pulmonary capillary bed in these patients is normally well oxygenated and therefore lies on the flat part of the oxyhaemoglobin dissociation curve, where any change in oxygen tension produces only a small change in the oxygen content of the blood. Thus in patients with right-to-left shunts nocturnal hypoventilation will have relatively little effect on the oxygen content or saturation of systemic arterial blood. In patients with chronic bronchitis and emphysema, on the other hand, daytime hypoxia is due to impaired gas exchange, different alveoli having a wide range of $\dot{V} / \dot{Q}$ ratios. Nocturnal hypoventilation in these patients causes a fall in arterial oxygen tension which is similar to that seen in normal subjects ${ }^{14}$ but their fall in oxygen saturation during REM sleep is much greater than in normal people because many of the alveoli start the night on the steeper part of the oxyhaemoglobin dissociation curve.

The age difference between the two groups has to be considered as a possible cause for the differences in nocturnal oxygenation. ${ }^{21}$ This is unlikely to be a major factor, however, as the duration of irregular breathing during sleep was the same in both groups.

It has been suggested that nocturnal hypoxaemia may provide a stimulus to development of secondary polycythaemia and pulmonary hypertension. ${ }^{21213}$ We have, however, observed greater nocturnal hypoxaemia in patients with chronic bronchitis and emphysema, who may have less secondary polycythaemia than patients with shunts, ${ }^{22}$ although this latter suggestion has been challenged. ${ }^{23}$ Our results do not suggest a major effect resulting from nocturnal hypoxaemia as in our study the packed cell volumes of the patients with shunts were not significantly different from those of the patients with bronchitis.

Non-invasive studies of oxygenation and breathing during sleep are being used increasingly for the assessment of patients being considered for domiciliary oxygen treatment and for those who pose diagnostic problems. This study suggests that the level of oxygenation while a patient is asleep 
cannot be predicted from the oxygen tension when he is awake unless the cause of the arterial hypoxaemia is known. Furthermore, although sleep studies are not recommended as a diagnostic test for right-to-left shunts, we suggest that if a patient who is appreciably hypoxic when awake fails to show further desaturation during sleep then possibly a right-to-left cardiac or intrapulmonary shunt should be borne in mind.

We thank Dr D de Bono and Dr HC Miller for allowing us to study patients under their care. We also thank Mrs C Hoy and Mrs M Miller for their technical assistance.

\section{References}

${ }^{1}$ Flick MR, Block AJ. Continuous in vivo monitoring of arterial oxygenation in chronic obstructive lung disease. Ann Intern Med 1977;86:725-30.

${ }^{2}$ Douglas NJ, Calverley PMA, Leggett RJE, Brash HM, Flenley DC, Brezinova V. Transient hypoxaemia during sleep in chronic bronchitis and emphysema. Lancet 1979;i:1-4.

${ }^{3}$ Wynne JW, Block AJ, Hemenway J, Hunt LA, Flick MR. Disordered breathing and oxygen desaturation during sleep in patients with chronic obstructive lung disease (COLD). Am J Med 1979;66:573-9.

${ }^{4}$ Koo KW, Sax DS, Snider GL. Arterial blood gases and pH during sleep in chronic obstructive pulmonary disease. Am J Med 1975;58:663-70.

${ }^{5}$ Littner MR, McGinty DJ, Arand DL. Determinants of oxygen desaturation in the course of ventilation during sleep in chronic obstructive pulmonary disease. Am Rev Respir Dis 1980;122:849-57.

- Catterall JR, Douglas NJ, Calverley PMA, et al . Irregular breathing and hypoxaemia during sleep in chronic stable asthma. Lancet 1982;i:301-304.

${ }^{7}$ Montplaisir J, Walsh J, Malo JL. Nocturnal asthma: features of attacks, sleep, and breathing patterns. $A m$ Rev Respir Dis 1982;125:18-23.

${ }^{8}$ Francis PWJ, Muller NL, Gurwitz D, Milligan DWA, Levison H, Bryan AC. Hemoglobin desaturation-its occurrence during sleep in patients with cystic fibrosis. Am J Dis Child 1980;134:734-40.
9 Stokes DC, McBride JT, Wall MA, Erba G, Strieder DJ. Sleep hypoxemia in young adults with cystic fibrosis. Am J Dis Child 1980;134:741-3.

${ }^{10}$ Weil JV, Kryger MH, Scoggin CH. Sleep and breathing at high altitude. In: Guilleminault C, Dement WC, eds. Sleep apnea syndromes. New York: Alan R Liss, 1978:119-23.

${ }^{11}$ Sutton JR, Houston CS, Mansell AL, et al. Effect of acetazolamide on hypoxemia during sleep at high altitude. N Engl J Med 1979;301:1329-31.

12 Flenley DC. Clinical hypoxia: causes, consequences and correction. Lancet 1978;i:542-6.

${ }^{13}$ Boysen PG, Block AJ, Wynne JW, Hunt LA, Flick MR. Nocturnal pulmonary hypertension in patients with chronic obstructive pulmonary disease. Chest 1979;76:536-42.

${ }^{14}$ Catterall JR, Douglas NJ, Calverley PMA, Shapiro CM, Brezinova V, Flenley DC. Hypoventilation is common; but sleep apnoea rare in transient nocturnal hypoxaemia of 'blue and bloated' bronchitics. Am Rev Respir Dis 1981;123: suppl: 113.

${ }^{15}$ Dornhorst AC. Respiratory insufficiency. Lancet 1955;i:1185-87.

${ }^{16}$ Documenta Geigy: scientific tables. 6th ed. Basel: JR Geigy SA, 1970:624.

${ }^{17}$ Douglas NJ, Brash HM, Wraith PK, et al. Accuracy, sensitivity to carboxyhemoglobin, and speed of response of the Hewlett-Packard 47201A ear oximeter. Am Rev Respir Dis 1979;119:311-3.

${ }^{18}$ Rechtschaffen A, Kales A, eds. A manual of standardised terminology, techniques and scoring system for sleep stages of human subjects. Bethesda, Maryland: National Institutes of Health, 1968. (Publication No 204.)

${ }^{19}$ Guilleminault C, van den Hoed J, Mitler MM. Clinical overview of the sleep apnoea syndromes. In: Guilleminault C, Dement WC, eds. Sleep apnoea syndromes. New York: Alan R Liss, 1978:1-12.

${ }^{20}$ Bulow K. Respiration and wakefulness in man. Acta Physiol Scand 1963; 59, suppl 209:1-110.

${ }^{21}$ Block AJ, Boysen PG, Wynne JW, Hunt LA. Sleep apnea, hypopnea and oxygen desaturation in normal subjects; a strong male preponderance. $N$ Engl J Med 1979;300:513-7.

${ }^{22}$ Vanier T, Dulfans MJ, Wu C, Desforges JF. Emphysema, hypoxia and the polycythemia response. N Engl J Med 1963;269:169-78.

${ }^{23}$ Stradling JR, Lane DJ. Development of secondary polycythaemia in chronic airways obstruction. Thorax 1981;36:321-5. 